\title{
Adolesanlarda Omurganın Sagital Düzlem Dizilimi
}

\section{Sagittal Plane Alignment of Spine in Adolescents}

\author{
Berivan Beril Kılıç ${ }^{1 *}$, Hakan Akgül ${ }^{2}$, Tuğba Kuru Çolak ${ }^{1}$ \\ ${ }^{1}$ Marmara Üniversitesi, , İstanbul, Türkiye \\ ${ }^{2}$ Trakya Üniversitesi, , Edirne, Türkiye \\ e-mail: fztbkilic@gmail.com,fzt.hakanakgul@gmail.com,cktugba@gmail.com \\ ORCID: 0000-0002-5588-4371 \\ ORCID: 0000-0002-3877-260X \\ ORCID: 0000-0002-3263-2278 \\ *Sorumlu yazar/ Corresponding Author: Berivan Beril Kılıç \\ Gönderim Tarihi / Received: 12.06.2020 \\ Kabul Tarihi / Accepted: 19.11.2020 \\ DOI: $10.34087 /$ cbusbed. 751886

\section{$\ddot{\mathbf{O z}}$}

Giriş ve Amaç: Omurganın fizyolojik sagital düzlem eğriliklerinden olan torakal kifoz ve lumbal lordozdaki değişiklikler adolesanlarda ilerleyen dönemlerde bir çok soruna yol açabilir. Bu çalışmada amacımız; sedanter, sporcu ve skolyoz tanısı olan adolesanların omurgalarındaki sagital düzlem parametrelerini değerlendirerek birbirleriyle karşılaştırmak ve saptanan anormal eğrilik varlığında bu eğriliklerdeki değişikliklerden kaynaklanabilecek olası yaralanmaları önlemektir.

Gereç ve Yöntemler: Çalışmaya 15-18 yaş aralığında olan 27 sedanter, 28 sporcu ve 18 adolesan idiopatik skolyoz (AİS) tanısı alan genç birey olmak üzere toplam 73 kişi (46 kız, 27 erkek) katılmıştır. Sagital düzlem parametrelerinin ölçümü için yerçekimine bağlı inklinometre (Baseline ${ }^{\circledR}$ Bubble ${ }^{\circledR}$ Inclinometer) kullanılmıştır. Bunlara ek olarak skolyoz tanısı alan katılımcıların gövde rotasyon açısı (Angle of Trunk Rotation, ATR) ve Cobb açısı değerleri de ölçülmüştür

Bulgular: Skolyoz grubunda kifoz açısı her iki gruptan da anlamlı olarak daha az bulunmuştur(p<0,05). Skolyoz grubunun lumbal lordoz açı değerleri, sporcu grubundan anlamlı olarak daha fazla bulunmuştur $(p=0,020)$. Skolyoz grubunun ortalama ATR değeri $9.67^{\circ}$ ve Cobb değeri ise $21.11^{\circ}$ idi. Cinsiyete göre incelendiğinde ise torakal kifoz açısı erkeklerde, lumbal lordoz açısı ise kızlarda anlamlı olarak daha yüksek bulunmuştur (sırasıyla $\mathrm{p}=0.000$; $\mathrm{p}=0,003$ ).

Sonuç: Sonuçlarımız AİS tanısı alan adolesanlarda sedanter ve sporcu gençlere göre fizyolojik sagital spinal parametrelerde anormal değişiklikler olduğunu; erkeklerde torakal kifoz açısının, kızlarda ise lumbal lordoz açısının daha fazla olduğunu göstermiştir. Spinopelvik kompleksin de değerlendirildiği, farklı spor branşılyla uğraşan sporcuların ve farklı eğrilik paternlerine sahip bireylerin de dahil edildiği çalışmalara ihtiyaç vardır.

Anahtar kelimeler: Adolesan idiopatik skolyoz, Lumbal lordoz, Torakal kifoz.

\section{Abstract}

Objective: Changes in thoracal kyphosis and lumbar lordosis, which are physiological sagittal plane curvatures of the spine, may cause many problems for adolescents in the future. This study aimed to compare the sagittal plane parameters of the spine of adolescents who are sedentary, athletes and diagnosed as adolescent idiopathic scoliosis (AIS), by evaluating them and to prevent possible injuries that may arise from changes in these curvatures in the presence of abnormal curvature.

Materials and Methods: A total of 73 people (46 girls, 27 boys) who are 15-18 years old were included in the study. Of which, 27 were sedentary, 28 were athletes and 18 were individuals with adolescent idiopathic scoliosis (AIS). Gravity-dependent inclinometer (Baseline ${ }^{\circledR}$ Bubble ${ }^{\circledR}$ Inclinometer) was used to measure sagittal plane parameters. In addition, the Angle of Trunk Rotation (ATR) and Cobb angle values of the participants who were diagnosed as AIS were measured.

Results: The kyphosis angle in the scoliosis group was significantly lower than both groups ( $\mathrm{p}<0.05)$. The lumbar lordosis angle values of the scoliosis group were significantly higher than the athletes' group $(p=0.020)$. The mean 
ATR value of the scoliosis group was $9.67^{\circ}$ and the Cobb value was $21.11^{\circ}$. When analyzed by gender, the thoracal kyphosis angle was significantly higher in boys and the lumbar lordosis angle was significantly higher in girls (respectively $\mathrm{p}=0.000 ; \mathrm{p}=0.003$ ).

Conclusion: Our results showed that adolescents diagnosed with AIS have abnormal changes in physiological sagittal spinal parameters compared to sedentary and athletes; thoracal kyphosis angle was higher in boys and lumbar lordosis angle was higher in girls. Studies that also evaluated the spinopelvic complex, involving athletes with different sports branches and individuals with different curvature patterns are needed.

Keywords: Adolescent idiopathic scoliosis, Lumbar lordosis, Thoracal kyphosis.

\begin{abstract}
1. Giriş
Son yıllarda omurga patolojilerinin tedavisinde, omurga sagital eğriliklerinin önemi de gittikçe artmaktadır [1,2]. Omurganın değerlendirilen en önemli sagital düzlem parametreleri torakal kifoz ve lumbal lorduzdur [1]. Yaş, cinsiyet, boy, kilo, vücut kitle indeksi (VKI), genetik faktörler gibi etmenler omurganın sagital düzlem eğriliklerini etkilemektedir [3]. Fizyolojik sagital düzlem eğriliklerinde azalma ya da artış; kişide postüral değişikliklere, yaralanma riskinin artışına, pulmoner fonksiyonda azalmaya, ağrı şikayetlerine, denge ve yürüme bozukluklarına, aktivite limitasyonu ile yaşam kalitesinde azalmaya neden olur [2,4,5,6,7].
\end{abstract}

Okul çağındaki adolesanlarda en yaygın olarak görülen spinal deformiteler; torakal hiperkifoz, lumbal hiperlordoz ve skolyozdur [8]. Uzun süreli kötü postürde kalma, yetersiz fiziksel aktivite ve obezite gibi diş faktörler, bu bireylerde kas dengesizlikleri ve kuvvetsizliğine neden olarak postüral deformitelerin ana nedenini oluşturmaktadır $[8,9]$.

Sporla uğraşan bireylerde ise spora özgü antreman postürü ve hareketler, spinal adaptasyonları etkileyen primer faktörlerdir [10]. Literatürde farklı spor branşlarında torakal kifoz ve lumbal lordoz açılarında değişiklikler olabileceği gösterilmiştir [7,11]. Basketbol oynayan adolesan erkeklerde de kifoz açılarında azalma rapor edilmiştir [3].

Adolesan idiyopatik skolyoz (AİS)'da torakal hipokifoz sık görülmektedir. Omurganın anterior kolumna'sındaki uzamanın posterior'a göre daha fazla olması torakal segmentlerde kifozda azalma ile; lumbal segmentlerde ise lordozda artışla sonuçlanmaktadır [12,13,14].

Fizyolojik spinal eğriliklerdeki değişikliklerin erken saptanması, tedavi yönetiminin planlanması ve yaralanmadan korunma açısından yararlı olabilir. Bu nedenle, bu çalışmada amacımız sağlıklı aynı yaş grubunda olan sedanter, sporcu ve skolyoz tanısı olan gençlerin omurgalarındaki sagital düzlem parametrelerini değerlendirmek, bu sagital parametreleri birbiriyle karşılaştırmak, saptanan anormal eğrilik varlığında kişiyi bilgilendirmek ve postüral bozukluklardan kaynaklanan olası yaralanmaları önlemektir.

\section{Materyal ve Metot}

Bu çalışmaya 15 Aralık 2019 - 05 Şubat 2020 tarihleri arasında sedanter, sporcu ve adolesan idiopatik skolyozu olan genç bireyler dahil edilmiştir. Özel Topkapı Final Anadolu Lisesi öğrencileri çalışmanın sedanter grubunu; İstanbul Kartal Dr. Lütfü Kırdar Eğitim ve Araştırma Hastanesi Ortopedi ve Travmatoloji Kliniği'ne başvuran ve uzman hekim tarafından AİS tanısı alan bireyler skolyoz grubunu; Galatasaray Spor Kulübü ile İstanbul Üniversitesi Spor Birliği Kulübü'nün alt yapı basketbol oyuncuları ise sporcu grubunu oluşturmuşlardır.

$\mathrm{Bu}$ çalışma Helsinki Bildirgesi'ne uygun olarak yürütülmüştür. Çalışma Marmara Üniversitesi, Sağlık Bilimleri Fakültesi Etik Kurul'u tarafindan onaylanmıştır. Çalışma öncesinde tüm bireyler çalışman hakkında bilgilendirilmiştir. Katılımcının 18 yaşında olması halinde kendisinden sözel ve yazılı olarak; 18 yaşından küçük olması halinde ise kendisinden sözel olarak, velisinden sözel ve yazılı olarak onam alınmıştır. Çalışmaya dahil edilme kriterleri; 15-18 yaş aralığında olmak, herhangi bir nörolojik, romatizmal ve ortopedik bir probleme sahip olmamak, AİS tanısı alan bireylerde skolyoz dişında konjenital ya da edinsel başka ortopedik probleme sahip olmamak, sporcu grubunda en az 5 yıldır basketbol oynuyor olmaktır. Çalışmadan dişlanma kriterleri; son 6 ay içinde omurgaya yönelik konservatif ya da cerrahi tedavi almış olmak, sporcu bireylerde postürü etkileyecek herhangi bir yaralanma geçirmiş olması idi.

Ölçümler için çalışmalarda güvenirliliği ortaya konmuş yerçekimine bağlı inklinometre (Baseline ${ }^{\circledR}$ Bubble ${ }^{\circledR}$ Inclinometer) kullanılmıştır [15,16]. Ölçümler aynı fizyoterapist tarafından bir paravanın arkasında, katılımcılar odaya tek tek alınarak yapılmıştır. Ölçüm sırasında katılımcidan ayakta, kendisini en rahat hissettiği pozisyonda durması istenmiştir. Torakal kifoz açısının ölçümü için inklinometrenin ayakları 'T1-T2' ve 'T12-L1' vertebra proseslerine yerleştirilerek, her iki noktadan elde edilen değerler toplanmıştır. Lumbal lordoz açısının ölçümü için ise inklinometrenin ayakları 'T12-L1' ve 'S1-S2' vertabra proseslerine yerleştirilerek her iki noktadan elde edilen değerler toplanmıştır. Ölçümler $3 \mathrm{kez}$ tekrar edilmiş ve ölçümlerin ortalaması alınarak sonuçlar kaydedilmiştir.

Tüm katılımcıların yaş, kilo, boy, cinsiyet gibi demografik özellikleri, geçirilmiş hastalık ve aile öyküleri, kifoz ve lumbal lordoz değerleri; skolyoz tanısı alan katılımcıların ise bunlara ek olarak gövde rotasyon açısı (Angle of Trunk Rotation, ATR) ve Cobb açısı değerleri araştırmacılar tarafından hazırlanan değerlendirme formuna kaydedilmiş ve bilgisayarda oluşturulan veri tabanına aktarılmıştır. Skolyoz tanısı alan katılımcılarda ATR ölçümünde skolyometre kullanılmıştır [17,18]. Öne eğilme pozisyonunda skolyometre ile ölçümden elde edilen maksimum gövde rotasyon değeri kaydedilmiştir. Cobb açısı ölçümleri, ayakta çekilen A-P radyografide eğriliğe katılan alt ve üst vertebraların plaklarına çizilen paralel çizgilere çekilen 
dikey çizgiler arasında kalan açının hesaplanmasıyla elde edilmiştir [19].

Veriler, SPSS versiyon 16.0 yazılımı (Statistical Package for Social Sciences, inc., Chicago, IL, ABD) ile analiz edilmiştir. Tüm analizlerde istatistiksel anlamlılık $\mathrm{p}<0,05$ düzeyinde değerlendirilmiştir. Verilerin normalitesi, Kolmogrov-Smirnov testi ile analiz edilmiştir. Ölçüm sonuçları gruplar arasında kıyaslanmıştır. Parametrik özellik gösteren verilerin analizinde üçlü grup kıyaslaması için One Way Anova testi, ikili grup kıyaslaması için Bağımsız örneklem t testi kullanılmıştır. Non-parametrik özellik gösteren verilerin analizinde üçlü grup kıyaslaması için Kruskal-Wallis testi, ikili grup kıyaslaması için Mann Whitney U testi kullanılmıştır. Cobb açısı, ATR, torakal kifoz açısı ve lumbal lordoz açısı arasındaki korelasyonu değerlendirmek için Spearman's Rho Testi kullanılmıştır.

\section{Bulgular ve Tartışma}

\subsection{Bulgular}

Çalışmaya 27 sedanter, 28 sporcu ve 18 skolyozu olan genç birey olmak üzere toplam 73 kişi (46 kız, 27 erkek) dahil edildi. Skolyozu olan adolesanların 3'ünde torakal, 11 'inde torakolomber, 4'ünde lomber eğrilik paterni vard1.

Tablo 1. Gruplara göre ortalama değerler ve standart sapmaları

\begin{tabular}{|c|c|c|c|c|}
\hline & \multicolumn{3}{|c|}{ Ort \pm SD (min-maks) } & \multirow[b]{2}{*}{$\underset{\text { değeri }}{P}$} \\
\hline Değiş̧kenler & $\begin{array}{c}\text { Skolyoz } \\
\text { Grubu } \\
(\mathrm{n}=18)\end{array}$ & $\begin{array}{c}\text { Sedanter } \\
\text { Grubu } \\
(\mathbf{n}=27)\end{array}$ & $\begin{array}{l}\text { Sporcu } \\
\text { Grubu } \\
(\mathrm{n}=28)\end{array}$ & \\
\hline Yaş & $\begin{array}{c}16.28 \pm \\
1.18 \\
(15.00- \\
18.00) \\
\end{array}$ & $\begin{array}{c}16.15 \pm \\
0.86 \\
(15.00- \\
18.00) \\
\end{array}$ & $\begin{array}{c}15.82 \pm \\
0.98 \\
(15.00- \\
18.00)\end{array}$ & 0.212 \\
\hline VKİ $\left(\mathrm{kg} / \mathrm{m}^{2}\right)$ & $\begin{array}{c}21.67 \pm \\
4.67 \\
(13.84- \\
33.41)\end{array}$ & $\begin{array}{c}21.70 \pm \\
2.86 \\
(15.62- \\
27.10)\end{array}$ & $\begin{array}{c}21.30 \pm \\
1.86 \\
(17.16- \\
25.43)\end{array}$ & 0.876 \\
\hline $\begin{array}{c}\text { Torakal } \\
\text { Kifoz } \\
\left.\text { Açısı ( }{ }^{\circ}\right)\end{array}$ & $\begin{array}{c}21.70 \pm \\
4.23 \\
(11.00- \\
29.00) \\
\end{array}$ & $\begin{array}{c}39.73 \pm \\
8.58 \\
(19.33- \\
53.67) \\
\end{array}$ & $\begin{array}{c}36.46 \pm \\
7.37 \\
(18.33- \\
49.33) \\
\end{array}$ & $0.000 *$ \\
\hline $\begin{array}{c}\text { Lumbal } \\
\text { Lordoz Açısı } \\
\left(^{\circ}\right)\end{array}$ & $\begin{array}{c}34.19 \pm \\
10.89 \\
(19.00- \\
55.00) \\
\end{array}$ & $\begin{array}{c}29.22 \pm \\
8.18 \\
(11.33- \\
44.33)\end{array}$ & $\begin{array}{c}27.12 \\
\pm 8.86 \\
(11.33- \\
45.00) \\
\end{array}$ & $0.042 *$ \\
\hline
\end{tabular}

min: minumum, maks: maksimum, Ort: ortalama, SD: standart sapma $\mathrm{p}<0.05$ : İstatistiksel anlamlılık düzeyi, VKİ: Vücut Kitle İndeksi

Tüm katılımcıların gruplara göre yaş, vücut kitle indeksi (VKI), torakal kifoz açısı ve lumbal lordoz açısı ortalama değerleri Tablo.1 'de gösterilmiştir. Üç grubun yaş ve VKİ ortalamaları istatistiksel olarak benzerdi ( $\mathrm{p}>0.05)$. Üç grubun torakal kifoz ve lumbal lordoz açıları kıyaslandığında ise gruplar arasında istatistiksel olarak anlamlı farklılık vardı.

Torakal kifoz açısı ortalama değerleri gruplar arasında ikili olarak kıyaslandığında skolyoz grubunun kifoz açısı değerleri $\left(21.7^{\circ}\right)$, sedanter $\left(39.73^{\circ}\right)$ ve sporcu $\left(36.46^{\circ}\right)$ gruplarından anlamlı olarak daha az bulundu $(\mathrm{p}<0.05)$ (Şekil.1).

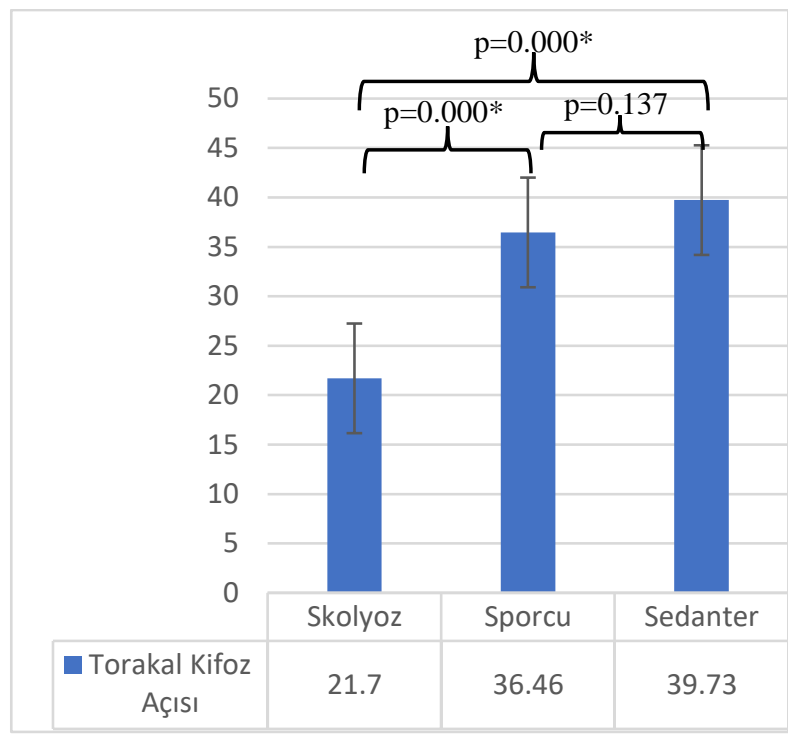

Şekil 1. Torakal kifoz açısı ikili grup karşılaştırmaları

Torakal kifoz açısı ortalama değerleri, cinsiyete göre incelendiğinde, erkeklerde kızlara göre anlamlı olarak daha yüksek bulunmuştur ( $\mathrm{p}=0.000)$ (Şekil 2). Torakal kifoz açısı her grupta katılımcıların cinsiyetine göre incelendiğinde ise yalnızca sedanter grupta erkeklerde $\left(43.53^{\circ}\right)$ kızlara $\left(36.69^{\circ}\right)$ göre daha yüksek bulunmuștur $(\mathrm{p}=0.037)$.

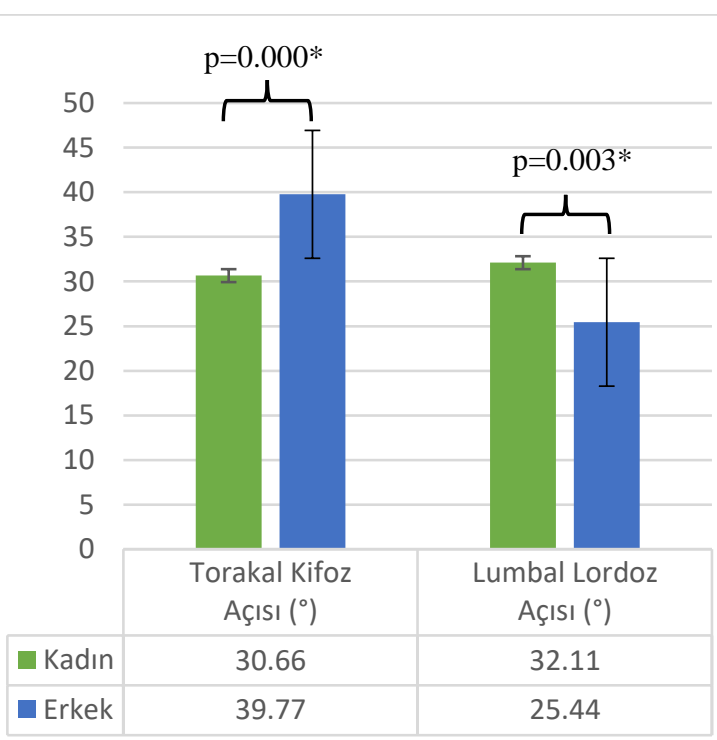

Şekil 2. Torakal Kifoz Açısı ve Lumbal Lordoz Açısı cinsiyete göre karşılaştırmaları

Lumbal lordoz açıları, ikili grup kıyaslamalarında skolyoz grubu değerleri, sporcu grubundan anlamlı olarak daha fazlaydı ( $p=0.020)$ (Şekil 3). Lumbal lordoz ortalama açıları cinsiyete göre incelendiğinde, kızlarda erkeklere göre anlamlı olarak daha yüksekti $(\mathrm{p}=0.003)$ (Şekil 2). 


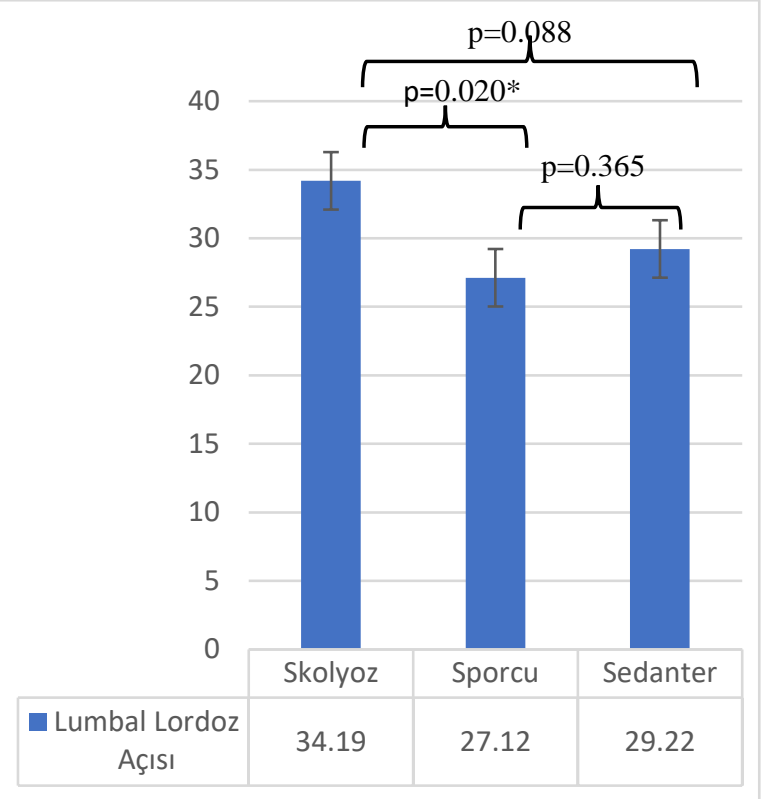

Şekil 3. Lumbal Lordoz Açısı ikili grup karşılaştırmaları

Calıșmaya katılan skolyoz grubunun ortalama ATR değeri $9.67^{\circ} \pm 4.91$ (aralık: $3^{\circ}-19^{\circ}$ ); ortalama Cobb değeri ise $21.11^{\circ} \pm 9.93$ (aralık: $10^{\circ}-40^{\circ}$ ) olarak idi. Skolyoz grubundaki değişsenler arasındaki korelasyon ilişkisi incelendiğinde; ATR ile Cobb açısı arasında; torakal kifoz açısı ile lumbal lordoz açısı arasında anlamlı, orta düzeyde pozitif korelasyon ilişkisi vardı (sirasiyla $\mathrm{r}=0.670, \mathrm{p}=0.002 ; \mathrm{r}=0.503 ; \mathrm{p}=0.033$ ).

\subsection{Tartışma}

Bu çalışmanın sonuçları; AİS tanısı alan adolesanların aynı yaş grubundaki sporcu ve sedanterlere göre daha az torakal kifoz açısına, sporculara göre ise daha fazla lumbal lordoz açısına sahip olduğunu göstermiştir. Çalışmadan elde edilen diğer bir bulgu ise, aynı yaş grubundaki adolesanlarda erkeklerin kizlara göre daha fazla torakal kifoz açısına, daha az lumbal lordoz açısına sahip olduğudur.

Literatürde skolyozu olan bireylerin \%44'ünün normal sagital düzlem açılarına sahip olduğu rapor edilmiştir [20]. Omurgada asimetrik yüklenmeler anormal spinal büyümelere neden olur [21]. AİS'te anterior kolumna yükündeki azalmanın anteriorda hızlı büyümeye, posterior kolumna yükündeki artışın ise posteriorda yavaş büyümeye neden olarak omurgada hipokifoza yol açtığı düşünülmektedir [12,14].

Abelin-Genevois ve ark. [20], özellikle skolyoz eğrilik paterni Lenke tip 1 ve 2 olan bireylerde torakal hipokifoz varlığını rapor etmişlerdir. Bir başka çalışmada ise çift eğrilik paterni ve torakal eğrilik paterni olan skolyotik bireylerde torakal kifozun anlamlı derecede azaldığını, lomber eğrilik paternlerinde ise lomber lordoz açısının arttığını ancak bu değişikliğin anlamlı olmadığı bildirilmiştir [22].Çalışmamızda skolyozu olan bireylerin çoğu torakolomber eğrilik paternine sahipti; primer torakal ve lomber eğrilik paternine sahip bireylerin sayısı az olduğu için sagital düzlem açılarında meydana gelen değişimler eğrilik paternine göre incelenememiştir.
Newton ve ark. [14] tarafından yapılan çalışmada primer torakal, torakolomber/lomber eğriliklerden oluşan skolyoz grubunda sağliklı bireylerden oluşan kontrol grubuna göre anlamlı olarak daha yüksek lumbal lordoz açısı varlığı bildirilmiştir. Bu çalışma ile uyumlu olarak, benzer eğrilik tipi olan katılımcılarımızda da daha yüksek lumbal lordoz açısına sahip olduğunu saptadık. $\mathrm{Bu}$ farklılığın oluşumuna, anormal anterior spinal büyümenin yanı sıra AİS’te sağlıklı bir omurgaya kıyasla değişmiş olan aksiyal ve koronal düzlemdeki rotasyon merkezinin de neden olabileceğini düşünmekteyiz. Değişmiş rotasyon merkezi, sagital düzlem eğriliklerinde meydan gelen değişimlerle kompanse edilmiş olabilir. Literatürde rotasyon merkezi ve sagital plan eğrilikleri arasında bir ilişki olduğunu gösteren çalışmalar mevcuttur [14]. Tüm bunlara ek olarak Grabara ve ark. [3], sporcularda yoğun egzersizlerin postüral kaslarda güçlenmeye neden olarak torakal kifoz ve lumbal lordozda değişikliklere yol açabileceğini bildirmişlerdir. Özellikle sporcu grubu ile karşılaştırdığımızda saptamış olduğumuz anlamlı farka, sezon içinde yapılan spora özgü antremanların ve postüral eksikliklere göre programlanmıș ağırlık antremanlarının da ek bir katkı sağlamış olabileceğini düşünmekteyiz. Bilgimiz dahilinde literatürde, AİS tanısı alan adolesanlar ve sporcu adolesanların sagital düzlem eğriliklerini karşılaştıran herhangi bir çalışma bulunmamaktadır.

Literatürde AİS'te hipokifoz varlı̆ğını bildiren daha önceki çalışmalarda, değerlendirme yöntemi olarak lateral radyografiden faydalanılmış ve segmental ölçümler yapılmıştır. $\mathrm{Bu}$ ölçümlerde en üst referans noktası T5 seviyesi olarak belirlenmiştir $[13,23]$. Çalışmamızda spinal eğriliklerin ölçümünde geçerliliği gösterilmiş olan inklinometreden yararlanıldı ve torakal kifoz açısı ölçümü torakal bölgenin daha üst seviyelerini de kapsayacak şekilde global olarak gerçekleştirildi. Moreira-pinto ve ark. [24], proksimal (T1-T5) ve distal (T5-T12) torakal kifozun, global kifoz oluşumuna farklı katkıları olduğunu ve proksimal segmentlerin servikal omurga ile anlamlı olarak ilişkili olduğunu bildirmişlerdir. $\mathrm{Bu}$ nedenle segmental değerlendirme yerine global değerlendirme yapmak omurga hakkında daha kapsamlı bilgi sağlayarak postüral değerlendirme ve tedavi takibi açısından daha yol gösterici olabilir.

Propst-Proctor ve ark. [25], sağlıklı ve skolyozu olan çocuklarda kifoz ve lordoz açılarını radyolojik olarak değerlendirmişlerdir. Skolyoz grubunda lordoz açısında artış, kifoz açısında ise her iki grubun ortalama değerlerinin benzer olduğunu ve sagital plan değişikliklerinin Cobb açısı derecesi ile ilişkili olmadığını rapor etmişlerdir. Çalışmamızda skolyoz grubunda lumbal lordoz açısında artış, torakal kifoz açısında ise azalma olduğunu belirlerken; benzer şekilde sagital düzlem değişiklileri ile Cobb ve ATR arasında ilişki saptamadık.

Takacs ve ark. [26], cinsiyetin hem torakal kifoz hem de lumbal lordoz üzerinde etkisi olduğunu bildirmişlerdir. Çalışmamızda cinsiyetin her iki açıya birden etkisinin olduğu; torakal kifoz açısının erkeklerde, lumbal lordoz açısının ise kızlarda daha fazla olduğu sonucuna ulaştık. 
Yalnızca sedanter grup erkeklerde daha yüksek torakal kifoz açısı saptadık. Bununla birlikte literatürdeki bazı çalışmalarda, cinsiyetin sadece torakal kifoz açısı üzerinde etkisi olduğu, bazılarında ise sadece lumbal lordoz açısı üzerinde etkisi olduğu gösterilmiştir [27,28,29]. Sonuçlardaki bu çeşitlilik; ölçümlerde tek bir standart olmamasından, ölçüm pozisyonu ile metodun farklılıklarından, ölçümlerin segmental ya da global olarak yapılmış olmasından kaynaklanmış olabilir.

$\mathrm{Bu}$ çalışmanın limitasyonları; skolyoz eğrilik paternlerine göre sagital düzlem ilişkisinin incelenememiş olması, spor yapma sürelerindeki farklılıkların parametreler üzerindeki etkilerinin karşılaştırılamaması ve sporcularda sezon sırasındaki antremanların sagital plan parametreleri üzerinde ne ölçüde etkili olduğunun tam olarak belirlenememesidir.

\section{Sonuc}

Bu çalışmada AİS tanısı alan adolesanlarda, sedanter ve sporcu gençlere göre fizyolojik sagital spinal parametrelerde değişiklikler olduğu; erkeklerde torakal kifoz açısının, kızlarda ise lumbal lordoz açısının daha fazla olduğu belirlenmiştir. Gelecekte yapılacak çalışmalarda değerlendirme parametrelerine spinopelvik kompleksin de eklenmesini, farklı spor branşı ile uğraşan ve farklı eğrilik paternine sahip bireylerin dahil edilerek bu farklılıkların fizyolojik sagital düzlem eğriliklerine etkilerinin incelenmesini önermekteyiz

\section{Referanslar}

1. Borges, P.A, Zelada, F, Dos Santos Barros, T.F, Letaif, O.B, da Rocha, I.D, Marcon, R.M, et al, Comparative Study of Sagittal Balance in Patients with Neuromuscular Scoliosis, Clinics (Sao Paulo, Brazil), 2017, 72, 8, 481-484.

2. Roussouly, P, Nnadi, C, Sagittal plane deformity: an overview of interpretation and management, European Spine Journal, 2010, 19 $11,1824-1836$

3. Grabara, M, Anteroposterior curvatures of the spine in adolescent athletes, Journal of Back and Musculoskeletal Rehabilitation, 2014 27, 4, 513-519.

4. Ishikawa, Y, Miyakoshi, N, Hongo M, Kasukawa, Y, Kudo, D Shimada, Y, Relationships among spinal mobility and sagitta alignment of spine and lower extremity to quality of life and risk of falls, Gait \& Posture, 2017, 3, 53, 98-103.

5. Aboutorabi, A, Arazpour, M, Ahmadi Bani, M, Keshtkar, A.A, Effect of spinal orthoses and postural taping on balance, gait and quality of life in older people with thoracic hyperkyphosis: protocol for a systematic review and meta-analysis, British Medical Journal Open, 2018, 8, 1, e015813.

6. Kuo, Y.L, Chung, C.H, Huang, T.W, Tsao, C.H, Chang, S.Y, Peng, C.K, et al., Association between spinal curvature disorders and injury: a nationwide population-based retrospective cohort study, British Medical Journal Open, 2019, 9, 1, e023604.

7.Ambegaonkar, J.P, Caswell, A.M, Kenworthy, K.L, Cortes, N Caswell, S.V, Lumbar lordosis in female collegiate dancers and gymnasts, Medical Problems of Performing Artists, 2014, 29, 4, 189 192.

8. Puzovic, V, Rotim, K, Jurisic, V, Samardzic, M, Zivkovic, B, Savic, A, Rasulic, L, The Prevalence of Spine Deformities and Flat Fee among 10-12 Year Old Children Who Train Basketball--CrossSectional Study, Collegium Antropologicum, 2015, 39, 3, 625-629.

9. Sedrez, J.A, da Rosa, M.I, Noll, M, Medeiros, F, Candotti, C.T, Fatores de risco associados a alterações posturais estruturais da coluna vertebral em crianças e adolescentes [Risk factors associated with structural postural changes in the spinal column of children and adolescents]. Revista paulista de pediatria: orgao oficial da Sociedade de Pediatria de Sao Paulo, 2015, 33, 1, 72-81.
10. Betsch, M, Furian, T, Quack, V, Rath, B, Wild, M, Rapp, W, Effects of athletic training on the spinal curvature in child athletes, Research in Sports Medicine, 2015, 23, 2, 190-202.

11. Muyor, J.M, López-Miñarro, P.A, Alacid, F, A comparison of the thoracic spine in the sagittal plane between elite cyclists and nonathlete subjects, Journal of Back and Musculoskeletal Rehabilitation,2011,24,3,129-135.

12. Sullivan, T.B, Reighard, F.G, Osborn, E.J, Parvaresh, K.C, Newton, P.O, Thoracic Idiopathic Scoliosis Severity Is Highly Correlated with 3D Measures of Thoracic Kyphosis. The Journal of Bone and Spine Surgery American Volume, 2017, 99, 11, e54.

13. Pizones, J, Núñez-Medina, A, Sánchez-Mariscal, F, Zúñiga, L, Izquierdo, E, Thoracic sagittal plane variations between patients with thoracic adolescent idiopathic scoliosis and healthy adolescents, European Spine Journal, 2016, 25, 10, 3095-3103.

14. Newton, P.O, Osborn, E.J, Bastrom, T.P, Doan, J.D, Reighard, F.G, The 3D Sagittal Profile of Thoracic Versus Lumbar Major Curves in Adolescent Idiopathic Scoliosis, Spine Deformity, 2019, 7, 1, 60-65.

15. Salamh, P.A, Kolber, M, The reliability, minimal detectable change and concurrent validity of a gravity-based bubble inclinometer and iphone application for measuring standing lumbar lordosis, Physiotherapy Theory and Practice, 2014, 30, 1, 62-67.

16. Hunter, D.J, Rivett, D.A, McKiernan, S, Weerasekara, I, Snodgrass, S.J, Is the inclinometer a valid measure of thoracic kyphosis? A crosssectional study, Brazilian Journal of Physical Therapy, 2018, 22, 4 310-317.

17. Amendt, L.E, Ause-Ellias, K.L, Eybers, J.L, Wadsworth, C.T, Nielsen, D.H, Weinstein, S.L, Validity and reliability testing of the Scoliometer, Physical Therapy, 1990, 70, 2, 108-117.

18. Coelho, D.M, Bonagamba, G.H, Oliveira, A.S, Scoliometer measurements of patients with idiopathic scoliosis, Brazilian Journal of Physical Therapy, 2013, 17, 2, 179-184.

19. Patia Patias, P, Grivas, T.B, Kaspiris, A, Aggouris, C, Drakoutos, E, A review of the trunk surface metrics used as scoliosis and other deformities evaluation indices, Scoliosis, 2010, 5, 12.

20. Abelin-Genevois, K, Sassi, D, Verdun, S, Roussouly, P, Sagittal classification in adolescent idiopathic scoliosis: original description and therapeutic implications, European Spine Journal, 2018, 27, 9 , 2192-2202.

21. Stokes I.A, Mechanical effects on skeletal growth, Journal of Musculoskeletal \& Neuronal Interactions, 2002, 2, 3, 277-280.

22. Mac-Thiong, J.M, Labelle, H, Charlebois, M, Huot, M.P, de Guise, J.A, Sagittal plane analysis of the spine and pelvis in adolescent idiopathic scoliosis according to the coronal curve type, Spine (Phila $\mathrm{Pa}$ 1976). 2003, 28, 13, 1404-1409. doi:10.1097/01.BRS.0000067118.60199.D1.

23. Yong, Q, Zhen, L, Zezhang, Z, Bangping, Q, Feng, Z, Tao, et al., Comparison of sagittal spinopelvic alignment in Chinese adolescents with and without idiopathic thoracic scoliosis, Spine, 2012,37,12,E714-E720.

24. Moreira Pinto, E, Alves, J, de Castro, A.M, Silva, M, Miradouro, J, Teixeira, A, Miranda, A, High thoracic kyphosis: impact on total thoracic kyphosis and cervical alignment in patients with adolescent idiopathic scoliosis, Spine Deformity, 2020, 10.1007/s43390-02000069-6. Advance online publication. https://doi.org/10.1007/s43390-020-00069-6.

25. Propst-Proctor, S.L, Bleck, E.E, Radiographic determination of lordosis and kyphosis in normal and scoliotic children, Journal of Pediatric Orthopaedics, 1983, 3, 3, 344-346.

26. Takács, M, Rudner, E, Kovács, A, Orlovits, Z, Kiss, R.M, The assessment of the spinal curvatures in the sagittal plane of children using an ultrasound-based motion analysing system, Annals of Biomedical Engineering, 2015, 43, 2, 348-362.

27. Gardner, A, Berryman, F, Pynsent, P, The development of Kyphosis and Lordosis in the Growing Spine, Spine, 2018, 43, 19,e1109-e1115.

28. Feng, Q, Jiang, C, Zhou, Y, Huang, Y, Zhang, M, Relationship between spinal morphology and function and adolescent non-specific back pain: A cross-sectional study, Journal of Back and Musculoskeletal Rehabilitation, 2017, 30, 3, 625-633.

29. Schlösser, T.P, van Stralen, M, Chu, W.C, Lm, T.P, Ng, B.K, Vincken, K.L, et al., Anterior Overgrowth in Primary Curves, Compensatory Curves and Junctional Segments in Adolescent Idiopathic Scoliosis, PloS one, 2016, 11, 7, e0160267. 
https://doi.org/10.1371/journal.pone.0160267.http://eder gi.cbu.edu.tr/ojs/index.php/cbusbed isimli yazarın CBUSBED başlıklı eseri bu Creative Commons AlıntıGayriticari4.0 Uluslararası Lisansı ile lisanslanmıştır.

(c) (7) (8) 